\title{
Sobre o que Não Aparece (ao Neopirrônico)
}

\author{
Hilan Bensusan \\ Paulo A.G. de Sousa*
}

Resumo: O artigo critica a posição filosófica neopirrônica defendida por Oswaldo Porchat Pereira (Porchat 5). Argumentamos que uma de suas noções básicas, a de fenômeno, carece de uma definição apropriada. Além disso, mostramos que o neopirronismo abre as portas para o irracionalismo e que a ciência modema traz problemas para essa postura.

Palavras-chave: neopirronismo - fenômeno - epokhé

Nosso objetivo neste artigo é criticar a postura filosófica neopirrônica, tal como apresentada e defendida por Oswaldo Porchat Pereira (Porchat 5). Sugeriremos que os problemas dessa postura advêm de que uma de suas noções fundamentais, a de fenômeno, carece de uma definição apropriada. Além disso, mostraremos que, procurando se opor ao dogmatismo, o neopirronismo (doravante NP) abre flancos ao irracionalismo; e que a ciência moderna traz mais problemas para o NP do que pode parecer à primeira vista. Antes, porém, cabe uma caracterização do NP.

Para tanto, precisamos caracterizar seus dois conceitos básicos: fenômeno e epokhé. Comecemos por este último. A epokhé é o estado em que se encontra aquele que se submente completamente a uma argumentação críti-

* Alunos de Pós-Graduação do Departamento de Filosofia da Universidade de São Paulo e do Departamento de Antropologia da Universidade de Brasília, respectivamente. 
ca, nos termos do NP. Este estado "conceme apenas a teorias, doutrinas e dogmatismos" (Porchat 5, p. 106). Ou seja, de um lado, uma teoria, uma doutrina - um conjunto de proposições filosóficas ${ }^{(1)}$-; de outro, o dogmatismo - um tipo de atitude proposicional ${ }^{(2)}$. Por isso, a epokhé neopirrônica é constituída pela intersecção de duas faces.

Uma delas é a suspensão do juízo sobre o conjunto das proposições filosóficas e a consequiente impossibilidade de utilizá-la para orientar a prática cotidiana. Esta face mostra que a visão neopirrônica do mundo não pretende ser especulativa - "Ela - a visão neopirrônica do mundo - não resulta de escolhas teóricas, não é uma construção da razão especulativa, falta-lhe também sistematicidade" (id., ibidem, pp. 107-108). Chamemos esta face, simplesmente, de suspensão do juízo. É ela que Porchat parece ter em mente quando diz:

"Estamos em epokhé a respeito de cada assunto filosófico sobre que nos debruçamos. (...) Nossa epokhé é tão-somente o estado em que nos encontramos quando uma investigação exaustiva empreendida com rigor e espírito crítico nos deixa precisamente sem condição para escolher ou decidir. (...) Temos o juízo suspenso sobre todas as asserções filosóficas que consideramos. E nossa expectativa obviamente não pode senão ser a de sermos analogamente levados à epokhé acerca de qualquer asserção filosófica que venhamos a considerar" (id., ibidkm, p. 86).

"Não dispondo de critérios para decidir da realidade ou verdade das coisas, estando em epokhé sobre teorias e doutrinas, não temos como nelas apoiar-nos para regular nossas ações na vida cotidiana" (id., ibidkm, p. 103).

Por essa face, ficam demarcados dois conjuntos de proposições: o conjunto das proposiçães filosóficas sobre o qual se dá a suspensão do juízo e o conjunto das proposições não-filosóficas que resiste à suspensão do juízo ${ }^{(3)}$.
A outra face diz respeito indistintamente a qualquer tipo de proposição. Nesta face, está destituída qualquer pretensão absoluta de verdade ou de correspondência com a realidade que se queira dar a qualquer proposição p. Por isso, a atitude proposicional "acreditar que p" - aquela que tem, segundo o NP, justamente esta carga ontológica e epistemológica dogmatizante - é substituída pela atitude "aceitar que p" (ou, na expressão de Porchat, "aparece-me que p") . Chamemos esta outra face, simplesmente, de mudança de atitude proposicional e as cuas atitudes proposicionais men-

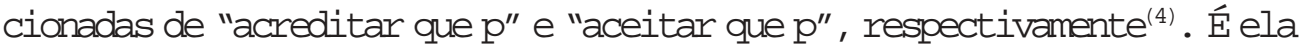
que Porchat parece ter em mente quando diz:

"(...) Nossa epokhé, assim, atinge igualmente todo e qualquer discurso apofântico (no sentido etimológico do termo), filosófico ou nãofilosófico, sofisticado ou trivial, acompanhado ou desacompanhado de uma pretensa fundamentação, todo e qualquer discurso que nos queira 'fazer ver' a verdade. Ela atinge toda e qualquer crença humana que, formulada num juízo, se proponha como conhecimento verdadeiro de uma dimensão qualquer do mundo" (Porchat 5, p. 89) .

Ainda que essas duas faces possam conformar rostos distintos (existe tanto o homem comum dogmático, como o filósofo não-dogmático), é apenas a sua intersecção que configura, para o NP, o estado de epokhé: uma face suspende o juízo acerca do conjunto das proposições filosóficas; a outra mantém, acerca das proposições do senso comum, uma atitude proposicional que evita conotações dogmáticas. Uma proporciona ao neopirrônico o olhar do homem da "praça de mercado"; a outra retira-lhe o dogmatismo:

"(...) O filósofo cético, que tem seu juízo suspenso sobre todas aquelas interpretações do fenômeno, ao confessar faltarem-lhe critérios e meios para decidir a controvérsia, se move tão-somente naquele terreno pré-filosófico e comum, onde tem lugar a descrição 
consensual da situação em comm 'experienciada' . Ele se reconhece incapaz de transcender a perspectiva modesta da praça de mercado" (Porchat 5, p. 96)

" (...) Relatamos as coisas que nos aparecem, descrevemos o fenômeno, servindo-nos trivialmente da linguagem comum. Entendemos 'é' como 'aparece' ou, melhor precisando, é como se disséssemos: 'Aparece-nos que o mel é doce' . (...) Ao dizer, por exemplo, que o mel é doce, não nos pronunciamos sobre a natureza real do mel ou da doçura (...)" (id., ibidem, p. 94).

Mas por que aceitar as proposições do senso comum e suspender o juízo sobre as proposições filosóficas? É que o NP pensa que as proposições do senso comm são suficientes para descrever aquilo que norteia a vida do neopirrônico - o fenômeno( ${ }^{(5)}$. Enquanto, ao contrário, uma proposição filosófica, porque interpreta o fenômeno, é uma forma de transcendêlo e, por isso, como já foi dito, não pode orientar a prática de um neopirrônico. Se o estado de epokhé, em sua primeira face, suspende o juízo sobre as interpretações do fenômeno e, na segunda, aceita as descrições do fenômeno, fica evidente que não se pode suspender o juízo sobre uma proposição filosófica e em seguida aceitá-la, pois, se este fosse o caso, uma proposição filosófica seria, ao mesmo tempo, interpretação e descrição do fenômeno - seria, ao mesmo tempo, filosófica e não-filosófica.

Assim, o neopirrônico contenta-se em viver "mergulhado na fenomenicidade" e usar a linguagem da vida cotidiana para dizer aquilo que lhe aparece como uma inquestionável necessidade:

"O que nos aparece se nos impõe com necessidade, a ele não podemos senão assentir, é absolutamente inquestionável em seu aparecer. Que as coisas nos apareçam como aparecem independe de nossa vontade. O que nos aparece não é, enquanto tal, dojeto de investigação, precisamente porque não pode ser objeto de dúvida. Não há sentido em argumentar contra o aparecer do que aparece, tal argumentação seria ineficaz e absurda. O que aparece, isto é, esse resíduo fenomênico da epokhé, esse conteúdo fenomênico de nossa experiência cotidiana, configura, por assim dizer, o dadb, ele nos é dadb" (Porchat 5, p. 91) .

Temos, então, as primeiras características do fenômeno. Ele impõe-se com a necessidade de um dado, é inquestionável, irrecusável e independe de nossa deliberação. Além disso, os fenômenos impõem-se tanto ao entendimento quanto à sensibilidade:

" (... ) Boa parte dos fenômenos se nos dão como sensíveis, impondose à nossa sensibilidade, enquanto boa parte também deles, talvez a maioria, se impõem e aparecem, antes, a nosso entendimento, se nos dão como inteligíveis. (. . . ) Me aparece também que tenho diante de mim um objeto que não se reduz àquilo de que tenho a percepção sensível. Aparece-me, por exemplo, que ele [o objeto que vejo] possui partes e propriedades que meus sentidos não estão alcançando, que ele permanece e dura quando ninguém o está observando etc." (id., ibidem, p. 92) .

Portanto, o fenômeno pode ser, além de sensível, inteligível ou, até, sensível e inteligível. Por fim, o NP caracteriza-o como relativo:

" (...) Diremos que o fenômeno se constitui essencialmente relativo, ele é relativo àquele a quem aparece. Nem mesmo entendemos como se poderia falar de um puro aparecer" (id., ibidem, p. 91) .

A partir destas definiçães, devemos ter em mente três níveis: o do fenômeno, o da descrição do fenômeno (das proposições do senso comum) , o da interpretação do fenômeno (das proposiçães filosóficas) . O estado de epokhé em sua primeira face suspende o juízo sobre as interpretações do fenômeno e na segunda altera a atitude proposicional acerca das descrições do fenômeno. 
Enfim, podemos entender o projeto do NP : a imersão no conteúdo irrecusável da experiência - o fenômeno, a suspensão do juízo acerca das interpretações do fenômeno e a aceitação das descrições do fenômeno. 0 $\mathrm{NP}$, então, pretende-se uma postura ateórica e antidogmática.

\section{Ceticismo quanto à Suspensão do Juízo}

Nesta seção, pretendemos mostrar que o NP não apresenta um critério para a delimitação do conjunto das proposições acerca do qual se deve suspender o juízo. Portanto, a própria suspensão do juízo torna-se arbitrária.

O NP não dá um critério de demarcação entre o conjunto das proposições filosóficas, que interpretam o fenômeno, e o conjunto das proposições do senso comum, que descrevem o fenômeno, porque, ao incluir o inteligível no domínio do fenômeno, não pode especificar o que seja uma interpretação filosófica. Pois só poderia fazê-lo se apresentasse uma distinção de natureza entre o que se impõe ao entendimento do homem comum, ao descrever os fenômenos inteligíveis, e o que se impõe ao entendimento do filósofo, ao interpretar os fenômenos. Porém, esta diferença não é traçada por Porchat, e acreditamos que dificilmente seria possível traçá-la, pois as intenpretações filosóficas parecem provir de fenômenos inteligíveis ${ }^{\left({ }^{6}\right)}$. Assim, não apresentando uma distinção de natureza entre descrição do fenômeno inteligível e interpretação do fenômeno, a face de suspensão do juízo tem um escopo apenas pragmaticamente delimitável.

Porchat tenta eximir-se das dificuldades que são acarretadas pela distinção entre descrição do fenômeno inteligível e interpretação do fenômeno através da seguinte estratégia:

" (... ) Não cabe pretender traçar fronteiras demasiado rígidas entre os domínios do dogma (da interpretação do fenômeno) e do fenômeno (inteligível) . (...) O assentimento a um dogma necessariamente comporta um elemento fenomênico e o recorte do mundo fenomênico jamais se pode pretender imunizado contra a presença sub-reptícia de ingredientes dogmáticos dissimulados e como embutidos no linguajar comum, vestígios eventuais de antigos mitos inextricavelmente incorporados ao senso comm de uma cultura. As fronteiras entre os dois domínios se estendem sobre uma terra de ninguém, onde os contornos se esvaem, pouco nítidos e mal delineados. Assim nos aparece" (Porchat 5, p. 112) .

Porém, postular esta "fuzziness" não resolve o problema da inexistência de um critério de distinção. No mais, esta "terra de ninguém" serve apenas para obscurecer o erro básico de categorização envolvido nesta distinção: ela não está erigida sobre nenhum critério formal, mas moldada em meras contingências. Isto fica claro no uso que Porchat faz, durante todo seu artigo, do predicado "filosófico" em expressões como "interpretação filosófica", "teoria filosófica", "significado filosófico", "asserção filosófica", "verdade filosófica", pois esta qualificação acrescenta apenas que estas expressões são oriundas de filósofos. Então, o domínio do "pré-filosófico" só pode significar aquilo que é produto do senso comum. No entanto, é claro que o senso comum tem pressupostos do tipo daqueles classificados pelo próprio NP como filosóficos. Por exemplo, a proposição "o objeto que vejo persiste quando não observado" parece não ser filosófica, para o $\mathrm{NP}$, apenas por nela crer o senso comum. Do mesmo modo, é impossível prever quais proposições podem vir a ser produtos da atividade filosófica. Imaginemos, por ilustração, uma sociedade onde o marxismo é a doutrina comum, e portanto, neste sentido, não-filosófico. Neste caso, o marxismo é a descrição do fenômeno para o NP, enquanto as proposições do nosso senso comum seriam interpretações filosóficas (bizarras) do que é fenômeno para tal sociedade.

Porchat tenta apoiar um critério para a suspensão do juízo apenas na distinção entre filosófico e não-filosófico, mas as proposições que, em alguns casos, são descrições do fenômeno, em outros, são interpretações do fenômeno. Tudo bem que se queira delimitar os usuários de certas proposições, mas essa delimitação não é suficiente para fundamentar o "peso filosófico" que o NP quer dar à dist inção entre descrição e interpretação, pois bem pode o filósofo descrever, como o senso comum interpretar. 
Um outro problema concernente à suspensão do juízo é que pelo menos uma proposição filosófica deve sempre ser aceita pelo NP, ainda que pareça sua aceitação ser por mera conveniência. A proposição "corpos humanos são outras pessoas" é filosófica no sentido do NP (basta ver a secular controvérsia, entre os filósofos, sobre outras mentes) e, acerca dela, o $\mathrm{NP}$ deveria, portanto, suspender o juízo. No entanto, o NP precisa aceitá-la como descrição da aparência, pois, se não o fizesse, não poderia ser uma posição crítica e com pretensões argumentativas. Sem ela, não poderia argumentar com quem quer que seja, em particular não poderia combater os dógmata dos filósofos:

"(...) Se um diálogo se estabelece entre o dogmático e o cético, se o cético consegue minar as bases sobre que aquele construiu a sua crença, se o dogmático passa a duvidar da 'evidência' em que se apóia ou descobre a problematicidade dos argumentos que o levaram à sua conclusão, então seu dógma perde sustentação e credibilidade, deixa por isso de aparecer-lhe o que antes lhe aparecia. (...) Com ele ocorre o que com qualquer um ocorre, quando se desfaz de uma crença que outrora julgara verdadeira: reconhece que não se tratava senão de uma 'aparência', fenômeno seu particular e de fato revestido de insuspeitada precariedade" (Porchat 5, p. 111) .

Deste modo, o NP tem que aceitar outras pessoas, pois, sem apelar para elas, todos os fenômenos seriam irremediavelmente particulares e não seria possível convencer o filósofo a abandonar o dogma. Neste caso, o único contra-argumento do NP residiria em aceitar uma tal proposição apenas como instrumento para combater os dógmata dos filósofos, da qual se desfaria assim que estes fossem convencidos. Seria, por assim dizer, como uma escada wittgensteiniana que se abandona depois de subir. Mas tal estratégia pouco ajudaria, pois o NP teria de recorrer à escada sempre que quisesse argumentar contra os dógmata dos filósofos.

Caso o NP queira escapar desses problemas, pode tomar dois caminhos: ou bem suspende o juízo também sobre as descrições dos fenômenos inteligíveis, ou bem não suspende o juízo sobre as proposições filosóficas. Se adota o primeiro, só pode aceitar as descrições dos fenômenos sensíveis, o que o reduz a um tipo estrito de empirismo. Se adota o segundo, pode aceitar também as proposições filosóficas, o que descaracteriza uma das faces do estado de epokhé, pois não há mais sobre o que suspender o juízo ${ }^{(7)}$. Passemos, então, à outra face da epokhé.

\section{A Ineficácia da Terapia}

Nesta seção tentaremos mostrar que a face restante do estado de epokhé mascara justamente aquilo que ela parecia excluir, pois, por trás das aparências, o neopirrônico esconde um olhar dogmático.

É bom frisar de início que, eliminada a primeira face da epokhé, nesta seção não entraremos no mérito da distinção entre descrição e interpretação do fenômeno, pois o que nos interessará será o embate entre cuas atitudes proposicionais: segundo $\circ \mathrm{NP}$, uma atitude dogmática - "acreditar que $\mathrm{p}^{\prime \prime}$ e uma atitude não-dogmática - "aceitar que $\mathrm{p}^{\prime}$.

Como diz Porchat, "a filosofia pirrônica se concebe como uma terapêutica e o dogmatismo é a doença que ela combate" (Porchat 5, p. 112) . Segundo o NP, tal dogmatismo é compartilhado tanto pelo comum dos homens, como pelos filósofos. Ele caracteriza-se por uma "obstinação do absoluto" que, no caso dos filósofos, vem à tona na construção de uma teoria do conhecimento que propõe que o conhecimento válido é aquele que tem fundamentação última e segura, de uma teoria da verdade que propõe que a verdade é a propriedade de representação correta da realidade e de uma moral baseada em valores absolutos. Enfim, caracteriza-se pelo afã de apodicidade tão caro a todos aqueles que buscam uma filosofia primeira.

Enquanto os dogmáticos pretendem fundamentar absolutamente suas doutrinas, o neopirrônico, diante da ausência de argumentos cabais que possam fundamentar quaisquer doutrinas (ou que possam decidir qual, dentre elas, é, absolutamente, a melhor), pretende substituir a crença nessas doutrinas por uma atitude, mais fraca, de aceitação. Esta atitude proposicional "aceitar que p", que o NP caracteriza como não-dogmática, pode ser enten- 
dida de chas maneiras: aceitar proposições específicas com alguma fundamentação argumentativa, mesmo que desprovida de pretensões de apodicidade; ou aceitar proposições específicas sem nenhum tipo de fundamentação argumentativa. Comecemos pela primeira.

Neste caso, seria de se esperar que um neopirrônico, a partir de algum critério, pudesse criticar as proposições específicas que formam o conteúdo de uma atitude proposicional alheia; bem como revisar as proposições específicas que ele aceita. Contudo, por definição, o único critério com que pode contar o neopirrônico para nortear sua aceitação de proposições é o fenômeno; e, este, para o $\mathbb{N}$, é "essencialmente" relativo:

"É certo também que enfatizamos o caráter relativo do fenômeno, lembrando sempre que o que aparece aparece a alguém. E que, restrito à experiência fenomênica, é à minha experiência fenomênica que estou restrito, é sempre meu fenômeno que exprimo, o que a mim aparece" (Porchat 5, p. 101) .

Se, além de relativo, o fenômeno é também irrecusável ("Não há sentido em argumentar contra o aparecer do que aparece, tal argumentação seria ineficaz e absurda", id., ibidkm, p. 91), o único critério de que se pode valer o neopirrônico é um pseudocritério - a restrição à irrecusabilidade e à relatividade do fenômeno impossibilita a revisão crítica do conteúdo das atitudes proposicionais, pois o máximo que se pode pretender argumentativamente é uma mudança da atitude proposicional de crença para a atitude proposicional de aceitação. A única estratégia que o NP pode utilizar é apelar para fenômenos comuns, isto é, apelar àquilo que aparece irrecusavelmente à maioria, sendo esta maioria definida histórica e culturalmente. Isto faria com que o indivíduo se conformasse ao fenômeno comum de sua cultura, o que pode ter consequiências desastrosas, se pensarmos que nenhum alemão na época do Terceiro Reich teria justificação para qualquer crítica às práticas nazistas. No mais, a inexistência de um critério para a revisão crítica do conteúdo de atitudes proposicionais reaparece no nível intercultural: o máximo que uma cultura de neopirrônicos não-fascistas pode pretender, diante de uma cultura de fascistas, é mudar sua atitude de crença para uma atitude de aceitação.

Portanto, a partir da definição de fenômeno, só é possível para o NP, a segunda maneira de entender a aceitação de proposições - aquela que relega qualquer exercício de fundamentação como inútil. Assim, contra as pretensões de universalidade do dogmático, $\circ \mathrm{NP}$ pode propor apenas uma adesão à relatividade e à irrecusabilidade do fenômeno; sendo que, mesmo esta proposição, não deve ser entendida como baseada em algum tipo de crença, mas naquilo que ele aceita simplesmente porque exprime o que the aparece.

Ora, o que o NP não percebe é que seu remédio - sua terapia para eliminar o dogmatismo -, ao mesmo tempo que cura, transmite a doença: a paralisia da crítica, o retorno do dogmatismo. Tanto a fundamentação absoluta como a ausência de qualquer fundamentação são o verso e reverso de uma mesma doença: o irracionalismo; pois, em verdade, o dogmatismo não reside, como quer $\circ \mathrm{NP}$, em um tipo específico de atitude proposicional, mas, principalmente, na impossibilidade de revisão crítica do conjunto das proposições, o conteúdo das atitudes proposicionais. Por isso, não basta o $\mathrm{NP}$ considerar, ao nosso ver apenas retoricamente, que:

"(...) pela própria natureza de seu método e procedimento, o pirronismo se constitui como um antídoto eficaz contra toda e qualquer forma de irracionalismo. Ao rejeitar os dogmatismos, ele conforma uma outra e diferente figura da racionalidade" (Porchat 5, p. 117) .

Pois o que realmente acontece é a configuração sub-reptícia de uma nova forma de irracionalismo, onde não existe a possibilidade de se justificar argumentativamente qualquer tipo de virtude, seja moral, seja epistêmica.

Em nossa opinião, o erro básico da diagnose neopirrônica, que também é o de grande parte do pensamento pós-moderno e relativista contemporâneo, é pressupor uma oposição simplista entre, de um lado, uma teoria da verdade, uma teoria do conhecimento e uma moral específicas e, de outro, a eliminação da verdade, a impossibilidade do conhecimento e a relati- 
vidade da moral - como se esta fosse, por excelência, a altemativa crítica e racional a se adotar diante do dogmatismo. Por isso, podemos dizer que o $\mathrm{NP}$, contrariamente ao melhor do pensamento contemporâneo, parece não ver nenhuma alternativa para a racionalidade senão a busca de uma filosofia primeira. Que existam outras alternativas fica claro quando se pensa na ciência - empresa epistemicamente virtuosa, por excelência.

\section{A Ciência contra o Neopirronismo}

Nesta seção tentaremos mostrar que, apesar de Porchat considerar que uma das vantagens do NP é ser este capaz de atender às demandas que a contemporaneidade apresenta a uma postura filosófica, o NP não pode compatibilizar-se com a ciência de hoje: ele não pode aceitá-la, nem sequer parcialmente, de um modo justificado.

A ciência, como empresa cognitiva bem-sucedida e como fonte de informações que pautam nossas decisões e a confiança que nelas depositamos, deve ser alvo de muitas atenções da filosofia contemporânea. Nos tempos helenísticos, a presença da ciência na vida cotidiana, como aponta o próprio Porchat (Porchat 5, p. 113), não era tão visível. E não o era apenas porque produzia poucos artefatos tecnológicos, mas porque a ciência da época não alcançara o sucesso da ciência contemporânea - sucesso na previsão e manipulação da natureza e sucesso na previsão de eventos que as teorias não foram construídas para prever.

Diante da atividade científica de hoje, as dificuldades mencionadas nas seções anteriores tornam-se mais graves. A ciência constrói teorias que não guardam associação imediata com aquilo que observamos. Elas podem ser entendidas como interpretações e/ou explicações dessas observações, em sentido semelhante ao que é conferido a tais expressões quando aplicadas às construçães dos filósofos. No entanto, diante das teorias científicas, Porchat, ao contrário do que faz com as teorias filosóficas, aceita-as como descrições das aparências. O NP poderia também, acerca do discurso teórico da ciência, suspender o juízo, mas neste caso, como naquele, encontra problemas.
No primeiro caso, para aceitar as teorias científicas como descriçães da aparência, o NP deve garantir que pode distinguir entre teorias científicas e teorias filosóficas. Para tanto, não basta repetir que são distintas as atitudes acerca destas teorias, pois isto já está suposto quando o NP considera que as teorias científicas são aceitas como descrições da aparência. Também de nada vale dizer que as teorias científicas são mais confimadas, pois as teorias filosóficas podem vir a ser igualmente confimadas - por exemplo, por meio de uma associação com hipóteses científicas particulares. Nada disso aponta para uma distinção de natureza ${ }^{(8)}$.

A única saída que resta ao NP é tentar substituir a distinção de natureza por alguma distinção que, ainda que contingente, possa sustentar a separação entre os dois "tipos" de teoria. Pode-se imaginar que seria possível encontrar algo assim na distinção entre a symphonía associada às teorias científicas e a diaphonía associada às suas correlatas filosóficas: as teorias científicas escapariam do tropo da diaphonía. De fato, o acordo gerado pelas teorias científicas, ainda que elas não tenham uma fundamentação apofântica, mostra que nem todo discurso teórico está sempre condenado à diaphonía. Com esta distinção, o NP poderia considerar como descrição da aparência apenas os discursos que trazem symphonía, reservando a suspensão do juízo para os demais. Porém, também aqui, o NP está arriscado a ver todas as proposições filosóficas, acerca das quais suspendeu o juízo, surgirem como corolários das teorias que aceita como descrição da aparência e com isto acabar com a diaphonía gerada pelos discursos filosóficos. De resto, a diaphonía não é condição suficiente nem necessária para um disarso ser filosófico.

Esse, porém, não é o único problema que o NP, com esta estratégia, enfrenta. Se aceita as teorias científicas, está aceitando não apenas interpretações teóricas do fenômeno, mas também descrições do fenômeno distintas daquelas providas pela linguagem da vida cotidiana, e com isto criase uma diaphonía quanto às próprias descrições do fenômeno ${ }^{(9)}$. Assim, além de não ter como distinguir de uma maneira conveniente teorias que revelam as profundezas do mundo fenomênico - elas exploram "um mundo fenomênico aberto a possibilidades ilimitadas de investigação" (Porchat 5, p. 116) - das que tentam interpretá-lo, o NP corre o risco de introduzir a 
diaphonía entre as próprias descrições do fenômeno. Além disso, nesta estratégia, $\circ \mathbb{N P}$ não consegue nem ao menos delimitar as teorias científicas, pois basta que se tenham em mente os episódios de controvérsia científica, para que se veja de pronto que a symphonía não é uma condição necessária para uma teoria ser científica. É devido a esta impossibilidade de traçar uma distinção entre uma teoria científica e uma interpretação filosófica do fenômeno (e a inexistência de critérios que pautem a aceitação de proposições) que Porchat pode até aceitar o que chama de realismo científico: considerar as entidades não-observáveis mencionadas nas teorias científicas como fenômenos inteligíveis.

Năo havendo possibilidade de traçar a distinção entre "teoria científica" e "teoria filosófica", o NP deveria suspender o juízo sobre todos os discursos teóricos. Restaria, então, apenas a possibilidade de o NP suspender o juízo acerca de parte das proposições de uma teoria científica, aquelas que ele não consideraria descrições do fenômeno. Neste caso, o NP assumiria, quanto à ciência, uma postura semelhante àquela dos empiristas, estratégia que, aliás, se combina melhor com a idéia de que a ciência modema é uma tékhne e com a pretensão do NP de manter-se na perspectiva da "praça do mercado". E poderia tentar fazê-lo apelando para a tradicional argumentação empirista: as teorias estão sempre subdeterminadas ${ }^{(10)}$ pelas dbservações, apesar da symphonía que acerca delas muitas vezes encontramos. No entanto, é fácil ver que aqui também há problemas. Uma vez que apenas aquilo que é determinado pela observação pode ser aceito como descrição da aparência, ter-se-ia que suspender o juízo quanto às descrições dos fenômenos inteligíveis. Se não fosse este o critério para demarcar aquilo que se aceita, o NP manteria um estranho empirismo que, ainda que não limitado àquilo que a observação pode determinar, não aceita a teoria toda. Um problema de todo empirismo é o chamado ceticismo seletivo (para uma crítica, ver os artigos de Churchland e Hooker em Churchland \& Hooker 2) , ou seja, a questão de justificar a crença em apenas parte de uma teoria. O problema do NP, ao aceitar parte das teorias científicas, é análogo - não pode oferecer um critério para distinguir o que aceita, como descrição da aparência, daquilo diante do que suspende o juízo. A cada teoria específica, o NP teria que arbitrariamente estabelecer o que aceita como descrição da aparência, pois o mesmo que acontece com a suspensão do juízo acerca das interpretações filosóficas do fenômeno aconteceria com a suspensão do juízo acerca das interpretações científicas.

Uma última consideração. Mesmo supondo, como faz Porchat, que seja possível ao neopirrônico aceitar o discurso científico como descrição da aparência, esta aceitação não pode repousar senão em uma atitude etnocêntrica que enaltece o conhecimento e a técnica de nossa cultura. Pois, impossibilitado de qualquer exercício de justificação, $\bigcirc \mathbb{N P}$ não pode nem fundamentar a ciência, nem explicar por que ela é virtuosa. Numa época falibilista e de epistemologia naturalizada, é mais razoável apresentar justificativas não-apodíticas para tal aceitação, em vez de contrapor justificaçães definitivas à ausência de justificações.

Vemos que em todos os casos não parece haver alternativa para que o $\mathrm{NP}$ compatibilize-se com a ciência. Na verdade, essa postura torna-se anacrônica diante de um empreendimento tão bem-sucedido como a ciência - e de nada adianta a artimanha de dizer que ela investiga com sucesso o fenômeno, pois, se tudo que dissemos é correto, isto não significa nada: tudo pode ser fenômeno. A ciência moderna, que tantos desafios põe ao empreendimento de pensar o conhecimento humano, não apenas deixa clara a inadequação de posturas como o NP, também nos convida a buscar alternativas filosóficas que levem em conta seu sucesso em desbravar os caminhos, muitas vezes acertados, mas não seguros, que nos possibilitam aumentar nosso conhecimento do mundo para além do que aparece.

Abstract: The paper criticizes the neo-pyrrhonian philosophical proposal defended by Porchat Pereira (Porchat 5). We argue that one of its fundamental notions, the notion of phenomenon, lacks an appropriate definition. Moreover we show that neo-pyrrhonism does not avoid irrationality and that modem science brings problems to this proposal.

Key-words: neo-pyrrhonism - phenomenon - epokhé 


\section{Notas}

(1) Em grande parte de seu texto, Porchat, revelando-se imoreciso na utilização dos termos "teoria" e "doutrina", utiliza-os como equivalentes a expressões como "tese metafísica" ou "interpretação filosófica do fenômeno". Utiliza, além disso, as expressões "teoria científica" e "doutrina científica". Para evitar confusões, pois este lado da epokhé concerne apenas a teorias (doutrinas) filosóficas, por enquanto, entenderemos uma teoria como um conjunto de proposições filosóficas. Na última seção do artigo falaremos sobre as teorias (doutrinas) científicas.

(2) Entendemos por "proposição" um conjunto de representações conceituais, eventualmente atualizadas lingüisticamente como o significado de uma sentença. Por "atitude proposicional" entendemos uma atitude qualquer com respeito a uma proposição. Assim, atitudes proposicionais podem diferir em duas dimensões: quanto ao tipo de atitude - crença, desejo, medo etc. -; e quanto ao seu conteúdo, a proposição - o sol nascerá amanhã, os anjos não têm sexo etc. (cf. Devitt \& Sterelny 3, p. 255) .

(3) Entre as proposições que resistem à suspensão do juízo, estão o subconjunto das proposições científicas e o subconjunto das proposições do senso comm. Por enquanto, na caracterização do $N P$, enfatizaremos apenas as proposições do senso comm. Sobre a aceitação, pelo NP, das teorias científicas, falaremos na última seção do artigo.

(4) É importante notar que, quanto às proposições acerca das quais se suspende o juízo, não se pode manter nenhuma atitude proposicional; no máximo, a suspensão de juízo sobre alguma proposição pode acarretar a mudança de atitude quanto a outras. É isso que acontece com Bas van Fraassen (van Fraassen 6), ao combinar suspensão do juízo, aceitação e crença. Ele considera que se deve manter quanto às proposiçcões das teorias que falam sobre não-observáveis uma atitude de aceitação desprovida de crença. Isto porque aquilo que poderia dar fundamento para considerá-las verdadeiras ou falsas são proposições que, por sua vez, merecem que, acerca delas, se suspenda o juízo. Deste modo, van Fraassen suspende o juízo quanto a certas proposições ("Todos os termos das teorias científicas referem"), aceita outras (as proposições que falam de não-observáveis) e acredita em outras (as que falam de observáveis).

(5) Porchat (cf. Porchat 5, p. 105) considera que tanto o fenômeno como suas descrições estão fora do escopo da suspensão do juízo.

(6) Pode-se ver também esta dificuldade como um problema na própria noção de fenômeno. Se o fenômeno é irrecusável, não deliberado e se impõe com a necessidade de um dado, não é possível que sejam fenômenos as propriedades não diretamente observáveis de um objeto, como a de dividir-se em partes ou persistir quando não observado. Nada disso nos é dado de modo irrecusável, não deliberado ou necessário. A descrição do fenômeno inteligível, por descrever algo inteligível, tem, acerca da recusabilidade, da deliberação e da necessidade, o mesmo estatuto que as interpretações do fenômeno.

(7) Pensamos que uma saída para o NP manter esta face seria tentar delimitar dois domínios diferentes de inteligíveis, um dos quais caracterizaria o fenômeno (inteligível). Algo semelhante encontra-se na distinção entre teoria primária e teoria secundária proposta em Horton 4.

(8) Poder-se-ia entender a suspensão de juízo quanto a teorias filosóficas que o NP propõe como uma suspensão de juízo acerca de quaisquer proposições que recebem certos tipos de justificação; por exemplo, as justificações que habitualmente os filósofos dão para suas proposições. Mas neste caso o NP não seria mais que uma crítica aos métodos de justificação habituais dos filósofos, não podendo de modo algum defender a impossibilidade de justificar a decisão (através de qualquer método) acerca de determinadas proposições.

(9) Isso fica claro quando se pensa em filósofos, como Churchland (cf., por exemplo, Churchland 1), que consideram que as descrições ordinárias dos eventos devem ser eliminadas e substituídas pelas descrições providas pelas teorias científicas. No caso do famoso problema de Eddington, em vez de se falar em "mesa", fala-se em "conjunto de moléculas".

(10) Utilizamos este termo para traduzir o inglês underdetermination. Ignoramos se alguma outra tracução para este termo já é corrente. 


\section{Bibliografia}

1. Churchland, P. Scientific Realism and the Plasticity of Mind. Cambridge, Cambridge University Press, 1979.

2. Churchland, P. \& Hooker, C. Images of Science. Chicago, The University of Chicago Press, 1985.

3. Devitt, M. \& Sterelny, K. Language and Reality. Oxford, Basil Blackwell, 1987.

4. Horton, R. Tradition and Modemity Revisited. In: Hollis, M. \& Lukes, S. Rationality and Relativism. Oxford, Basil Blackwell, 1982.

5. Porchat Pereira, O. Sobre o que Aparece. In: discurso, no 19, São Paulo, 1992.

6. van Fraassen, B. The Scientific Image. Oxford, Oxford University Press, 1980. 